\title{
CURRÍCULOS E INFÂNCIAS NÔMADES
}

Sueli Soares da Silva Moreira ${ }^{(*)}$ Maria Riziane Costa Prates ${ }^{(*)}$ Cândida de Nadai Ton ${ }^{(* *)}$

Este texto problematiza as situações de nomadismo dos currículos escolares por professores e crianças em um Centro Municipal de Educação Infantil, na cidade de Vitória - ES. Apresenta experiências enquanto sensibilidade de criação e invenção curricular, pelos modos de conexão com as diferentes maneiras de ensinar e aprender.

Por currículo compreendemos tudo o que acontece na escola, como modo de existência e traçados de planos que se deixa percorrer por fluxos intensivos. Currículos que buscam combater representações fixas e recognições, para criar. "Dizer de uma vida qualquer, como é a curricular, é arrastar, simultaneamente, seu esgotamento para fora das lógicas do possível e reivindicar o acesso da areia do deserto ao liso espaço do mar que ondula" (AMORIM; ROMAGUERA, 2015, p.112). Esse movimento de reinvenção conduz aos espaços nômades.

Por nomadismo, entendemos com Lins (2005, p.123), que "devemos criar dispositivos alegres para passar realidades muitas vezes duras, segundo a possibilidade de cada criança, de singularidade única, não repetitiva". O sujeito-criança e os currículos nômades, nesse contexto, são aqueles que se formam e se reinventam nos entrelugares, na itinerância de um cotidiano escolar que vai se compondo em lógicas de alteridade, pela invenção de novos mapas e mundos a serem desbravados pela sensação de pertencimento, criação de novos territórios, que não são espaços geográficos, mas afetivos, sensíveis; espaços e tempos de solidariedade e aprendizagem.

Aprendizagens e invenções curriculares que, como apontam as Diretrizes Curriculares Nacionais para a Educação Infantil (BRASIL, 2010), precisam se configurar em movimentos de cisão com práticas pedagógicas que historicamente tomaram a criança como alguém a ser governado pelos adultos detentores do saber, determinando as possibilidades da criança; por tessituras curriculares que articulem experiências e "[...] os saberes das crianças com os

\footnotetext{
${ }^{(*)}$ Graduada em Pedagogia pela Universidade Vila Velha.

${ }^{(* *)}$ Doutora em educação, Mestrado, Especialização e Graduação em Pedagogia pela Universidade Federal do Espírito Santo (UFES). Professora da Universidade Vila Velha, na graduação em Pedagogia, Pedagoga do Núcleo de Acessibilidade (NACE-UVV), Professora do Mestrado em Segurança Pública (UVV). É professora da Educação Infantil no município da Serra, atuando na formação continuada de professores (Centro de Formação-SEDU-SERRA).

${ }^{(* * *)}$ Formada em Direito, Pós-graduação em Direito Judiciário e mestranda em Segurança Pública na Universidade Vila Velha.
} 
conhecimentos que fazem parte do patrimônio cultural, artístico, ambiental, científico e tecnológico, de modo a promover o desenvolvimento integral de crianças de 0 a 5 anos de idade" (p.14).

A criança no contexto coletivo da educação infantil, portanto, precisa ser considerada como “[...] sujeito histórico e de direitos que, nas interações, relações e práticas cotidianas que vivencia, constrói [...], brinca, imagina, fantasia, deseja, aprende, observa, experimenta, narra, questiona [...], produzindo cultura (BRASIL, 2010, p.14). Pensar infâncias requer pensar em constituições nômades, infância como “começo, interrupção, estrangeiridade do pensamento" (KOHAN, 2015, p.223).

A tentativa foi compreender como as crianças são acolhidas ao chegarem à escola, quais saberes são produzidos nas relações entre docentes e crianças em situação de nomadismo.

O nomadismo desordena identidades. Cruz e Heillesheim (2011) apontam que os nômades modificam os espaços por onde passam, desmistificam saberes, inauguram modos e aproximações entre escola e crianças que vagueiam. Indagamos, assim, o que pode um encontro em meio às tessituras curriculares? O que as crianças dizem em seus movimentos nômades? Como é ouvido o que é dito pelas crianças? Como elas escapam e inventam os espaços escolares?

\section{A ESCOLA COMO QUINTAL VIVO}

Por ser a escola um campo transitório de crianças e professores, por motivos variados, os quais desenham paisagens cartográficas continuamente, desfazendo e reconstruindo mundos, a intenção foi buscar um espaço onde os processos migratórios acontecessem intensamente para compreender o que se passa nesse cotidiano escolar.

Adentramos para um Centro Municipal de Educação Infantil (CMEI) na cidade de Vitória em que as migrações acontecem em função das crianças em situação de risco social. O CMEI, que aqui chamaremos de Quintal, possui em sua adjacência o abrigo Fé e Alegria, e pela sua proximidade, as crianças em idade escolar, que corresponde a Educação Infantil (zero a cinco anos de idade), estão matriculadas nessa escola.

Assim, aproximamo-nos desse campo para realizar uma pesquisa qualitativa, pelas redes de conversações nos seus imbricamentos com a cartografia das escolas. Analisando as relações, sentimentos, sensações das crianças que chegam à escola e suas relações com os professores.

Contrapondo a cartografia de territórios estáticos - a cartografia aqui como método de pesquisa procura cartografar paisagens psicossociais. A cartografia, nesse caso, acompanha e faz ao mesmo tempo que o desmanchamento de certos mundos - sua 
perda de sentido - e a formação de outros mundos: mundos que se criam para expressar afetos contemporâneos, em relação aos quais os universos vigentes tornaram - se obsoletos (ROLNIK, 2006, p.23).

Nosso primeiro contato com a escola foi acolhedor. Logo no portão, as funcionárias que trabalham na área de segurança da escola, ao nos ver com a camiseta da Universidade, puxaram conversa pedindo informações dos cursos existentes e em seguida levaram-nos até às professoras. Conversamos com os docentes sobre a pesquisa e o público alvo, crianças em atual situação migratória, por compreender que os saberes que desenvolvem são oriundos de diferentes territórios.

As crianças nômades modificam a velocidade da escola, produzindo aceleração, condensando o ano escolar em poucos dias ou semanas. Os nômades, apesar dos esforços de apreensão, nunca estão onde se espera, imprimindo velocidade absoluta aos movimentos. Sempre em busca de novas paisagens. Escapam aos controles, às contagens, às regulações, funcionando como máquinas de guerra que implodem a disciplina escolar (CRUZ; HEILLESHEIM, 2011, p. 86).

Ao ouvir nossa proposta de pesquisa, as professoras nos aconselharam a desenvolvê-la em uma escola de Ensino Fundamental, pois as crianças da Educação Infantil, por serem pequenas poderiam não responder aos nossos anseios. Essa fala foi como música aos nossos ouvidos e nos fez ter a ideia de que a educação infantil era o lugar certo para desenvolvimento de pesquisa, por compreender que sentimentos, sensações e relações não possuem idade determinada para acontecer. Como aponta Prates; Rodrigues (2012, p. 132), “[...] Cabe ao professor e à criança se deslocarem das 'verdades', que, por vezes, se fazem inquestionáveis, lançando-se a outras possibilidades, desvinculando-as das formas hegemônicas para outros campos possíveis do acontecimento [...]”.

É preciso que a gente entre em contato com as coisas para que as coisas nos façam pensar e sair do lugar. Sair do lugar não é simplesmente se deslocar; envolve outro tipo de deslocamento. Trata - se de um deslocamento das ideias prontas, daquilo que está naturalizado, do "é assim mesmo", do óbvio, sem surpresas, do que parece estar desde sempre já dado. Em outras palavras, trata - se de um deslocamento do olhar (PUCHEU, 2007, p. 67).

Adentramos o universo escolar, observando as cenas, as montagens, produções, falas, imagens, harmonias e desarmonias, manifestações das crianças, em busca dos entendimentos das vidas nômades. Nesse movimento, fomos utilizando os nossos registros como forma de disparar conversas com alguns funcionários que tinham mais contato com as crianças, como a pedagoga, a coordenadora, a professora e o professor de educação física, compreendendo a potência das redes de conversações. 
Por rede de conversações entendemos com Carvalho (2009, p. 204-205) “[...] o acolhimento dialogado, um dispositivo, um apoio ao processo de conhecimento das necessidades [...], a centralidade para a compreensão do humano, da participação da linguagem e das emoções no que, na vida cotidiana, denominamos como conversar".

Destacamos que ao argumentarmos com os professores sobre a pesquisa com crianças nômades e suas singularidades, eles entendiam como nômades, apenas as crianças residentes no abrigo, conhecido pelas crianças como "Casa Rosa". A Casa Lar é um local, situado na região de Vitória, ES, que abriga crianças de até doze anos de idade que, se encontram em situação de risco social.

Iniciamos, assim, uma conversa com alguns docentes especialmente no sentido de indagar sobre a singularidade das crianças ou como "um desafio de abrir mão do controle de significados, pelo exercício do diálogo e da escuta sensível - uma escuta que acolhe a experiência de sua transformação como constitutivo da própria experiência” (PEREZ, SAMPAIO, 2012. p. 397).

Por experiência, entendemos com Larrosa (2002, p. 25-26), como "o que nos passa, o que nos acontece, o que nos toca. Não o que se passa, não o que acontece, ou o que toca. A cada dia se passam muitas coisas, porém, ao mesmo tempo, quase nada nos acontece”. Experiência como algo que nos desperta para outros modos de pensar e agir.

Interessa pensar a composição dos currículos e das infâncias como experiência. "Somente o sujeito da experiência está, portanto, aberto à sua própria transformação” (LARROSA, 2002, p. 26). Partimos, assim, para uma produção de dados a partir de conversas com os docentes para compreender as articulações dos saberes e sua movimentação na escola e na vida das crianças que passam por ela.

\section{DOS ESPAÇOS SEDENTÁRIOS ÀS INVENÇÕES NÔMADES}

A escola, se tomada como espaço que ordena pessoas, sedentário, contrapõe aos nômades por seus locais indefinidos, lisos, contendo em suas características somente sinais que deixam de existir ainda em seu trajeto. Esses espaços não existem sozinhos. "O espaço liso não para de ser traduzido, transvertido num espaço estriado; o espaço estriado é constantemente revertido, devolvido a um espaço liso", (CRUZ; HILLESHEIM, 2011, p. 86). 
Ao iniciar a pesquisa, dias depois em uma sala com crianças de idade entre quatro e cinco anos, conhecemos Henrique, Sandro e Iara ${ }^{1}$ que, juntamente com outras crianças, norteariam a pesquisa com suas maneiras, costumes e expressões. Mas, quem são elas?

Em um breve relato sobre essas crianças, fomos informadas pela Pedagoga do CMEI, que Henrique mora no Abrigo há dois anos juntamente com seu irmão Luan. Os irmãos possuem uma irmãzinha de três anos. A mesma vive com uma família acolhedora e apesar de estudarem na mesma escola, os dois meninos não sabem que tem uma irmã nessa escola e que às vezes fazem as refeições um ao lado do outro sem sequer imaginar que são irmãos.

O programa Família acolhedora cadastra e capacita famílias que tem o interesse em acolher crianças ou adolescentes que se encontram em situação de risco social, para que amparem essas crianças, possibilitando uma convivência familiar. Os pré-requisitos para se inscrever no Programa Família Acolhedora são: disponibilidade afetiva; ter idade entre 25 e 55 anos; estar em boas condições de saúde física e mental; ter boa situação financeira e livre do uso de entorpecentes.

Enquanto a irmã vive com uma família acolhedora, os irmãos encontram - se em processo de adoção. Henrique possui uma deficiência física e se encontra com as duas pernas engessadas para correção de um problema de locomoção em que nasceu com ele.

A questão de Henrique é sensível, pelo fato colocado pelas psicólogas em momento de visita à escola, pois ele tem ficado boa parte de seu tempo em uso do gesso, dificultando suas atividades e brincadeiras nos diferentes espaços da escola. As professoras comentam que o conheceu já em uso do gesso e que ao longo de dois anos estudando nessa escola, esteve sem o gesso apenas durante três meses. Isso porque, deverá usá-lo durante toda sua infância, ou seja, o menino terá uma infância comprometida, pois os médicos dizem que ele deverá passar por uma cirurgia após o seu crescimento corporal.

Na sala de aula, o Henrique é muito participativo. A escola tem todo um cuidado em apoiálo com almofadas para que execute as atividades e acompanhe o que está sendo proposto. A questão é que o gesso é muito pesado e não favorece a articulação das pernas, deixando o menino com as pernas eretas. Talvez, esse seja um motivo de às vezes nos depararmos com ele andando vagarosamente pela sala a contemplar os trabalhos dos colegas e, é claro, tecendo seus comentários, dando opiniões, provocando discussões.

\footnotetext{
${ }^{1}$ Todos os nomes usados no texto são fictícios.
} 
A maior preocupação das psicólogas é com a perda da infância pelo Henrique em decorrência da questão de locomoção, mas, ainda bem que existem outras maneiras de fazer aulas e, apesar do gesso, ele consegue brincar de "carrinho" na terra e em pé, como a foto abaixo apresenta. Esses são apenas alguns exemplos que acontecem nas aulas de Educação Física, onde todos participam independente das questões que trazem.

\section{Foto 1. Corrida de tampinha e Foto 2: Brincando na terra.}

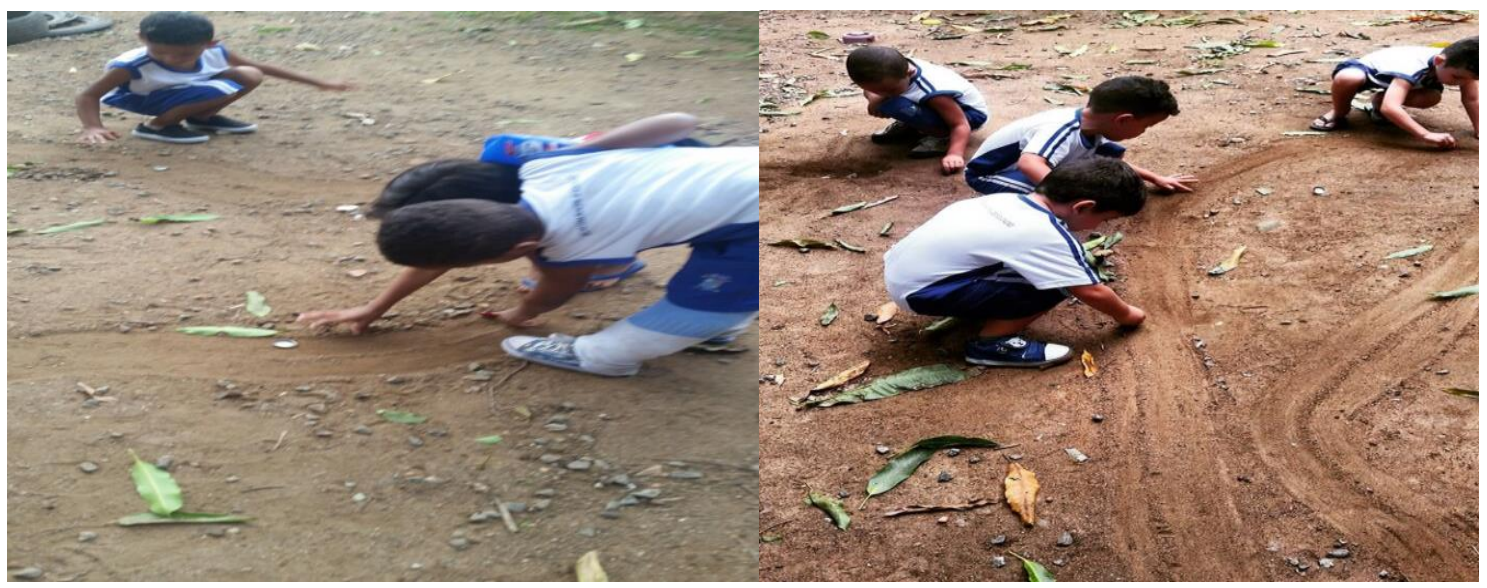

Fonte: Aula de educação física no centro de educação infantil.

Em uma brincadeira que exige um movimento corporal intenso, o Henrique consegue desenvolver modos diferentes de participação. Ele sempre dá um jeito de participar, para encontrar com seus colegas, moradores também da mesma Casa. Esses meninos estão aguardando pelo processo de adoção, que, pelos relatos de funcionários da escola, deverá acontecer em breve.

A entrada do Henrique, assim como as outras crianças moradoras do abrigo "Fé e Alegria", no processo de adoção indica que as chances de reinserção na família biológica esgotaram. Tendo em vista que estudam na mesma escola da irmã e não se conhecem, talvez, possamos ousar pensar que no caso de uma adoção, as chances de serem apresentados diminuam, tendo em vista a possibilidade de mudarem de escola.

Sandro e o irmão Antônio estão na Casa lar também há dois anos. Estudam na mesma escola e não se encontram em processo de adoção, permitindo-nos compreender que existem chances de serem reinseridos novamente no contexto familiar biológico.

Os motivos que levam essas crianças a estarem afastadas de suas famílias são os mais variados possíveis, desde agressão física, abandono, até o uso de entorpecentes praticados pelos familiares. Importa ressaltar também, que mesmo alguns entorpecentes sendo considerados lícitos, como é o caso do álcool, seu uso em excesso pode provocar agressões, maus tratos e tantas outras ações que podem prejudicar as crianças no ambiente familiar. 
Tendo seus direitos violados, medidas protetivas são necessárias para conter o risco proporcionado às crianças em situação de violência, garantindo-lhes o direito à vida. Sendo assim, o Tribunal de Justiça do Distrito Federal e dos Territórios destaca como competência e destinação das medidas protetivas:

Cabe ao Juiz da Vara da Infância e da Juventude aplicar as medidas protetivas previstas no artigo 101, incisos I a IX, do Estatuto da Criança e do Adolescente, quais sejam: Encaminhamento aos pais ou responsável, mediante termo de responsabilidade; Orientação, apoio e acompanhamento temporários; Matrícula e frequência obrigatórias em estabelecimento oficial de ensino fundamental; Inclusão em programa comunitário ou oficial de auxílio à família, à criança e ao adolescente; Requisição de tratamento médico, psicológico ou psiquiátrico, em regime hospitalar ou ambulatorial; Inclusão em programa oficial ou comunitário de auxílio, orientação e tratamento a alcoólatras e toxicômanos; Acolhimento institucional; Inclusão em programa de acolhimento familiar; Colocação em família substituta (BRASIL, 1990, p.56.).

Nesse contexto, as crianças da Casa Lar se tornam nômades, nesses caminhos de idas e vindas, na tentativa de serem reinseridas às suas famílias de origem ou de serem adotadas. Nessas tentativas são acompanhadas por assistentes sociais, inclusive no espaço escolar.

Experimentam uma infância nômade, pois a própria condição já é de nomadismo. Nessas movimentações ou esperas por adoção, que poderão acontecer ou não, conhecem várias pessoas que podem dizer até logo ou adeus. Talvez, essas variadas despedidas sejam um dos motivos para que eles não chorem ao chegar à escola. É como se já tivessem naturalizado as despedidas e não lhes coubessem mais o choro, nesses momentos!

Durante o tempo em que estivemos na escola, notamos que eles não abraçam as pessoas, o que se deu também com a nossa presença. Eles não se despedem. Talvez, devemos nos considerar também pessoas nômades em suas vidas.

Conhecemos a Iara, uma linda menina que possui uma situação um pouco diferente. Mora com a mãe, porém migra bastante de escola devido à perda de alguns familiares para o tráfico de entorpecentes. Foi matriculada na escola Quintal, três vezes em 2017. Sua mãe, durante a moradia em Vitória, vive a maior parte do tempo nos espaços destinados aos trabalhos para o carnaval, onde desfila com Iara. A menina é passista, uma garotinha que tem samba no pé.

A Iara se mostra sensível e emotiva! Podemos presenciar seu choro nas brincadeiras, ou até mesmo no horário de saída em que sempre imagina e comenta que a mãe não virá buscá-la. Um 
choro que transmite o medo de perder algo. No caso dos meninos do abrigo Fé e Alegria, a ausência de choro demonstra uma perda como fato.

Todas essas características nos fizeram criar um desejo de produção e ser atravessadas por bons encontros espinosanos que aumentaram a potência de pensar e agir, mas também, de perceber que esses prenúncios dependem do contexto vivido por cada criança, onde chorar tem um significado e não chorar poderá ter um significado ainda maior.

\section{CRIANÇAS, AULAS E INVENÇÕES...}

Fomos acompanhando os processos de ensino aprendizagens no sentido de compreender como esses processos são garantidos nos dias de hoje, mas também com a inquietude em descobrir por onde passam as alegrias e tristezas, já que as crianças que se encontram em situação de vulnerabilidade, mesmo com os cuidados transmitidos pelos funcionários da Casa Lar e a atenção especial da escola, são crianças marcadas por separações familiares e tentativas de adoção, que às vezes não são concluídas.

Adentramos para uma sala de aula e fomos seguindo o fluxo. Era hora da aula de Educação física. Ao chegarmos no espaço da aula, sentimos um estranhamento. Olhamos a terra escura misturada com britas e ficamos nos perguntando como será essa aula sem traves, cordas, bambolês, redes, etc. Era um terreno com algumas árvores frutíferas que nos permitiam escolher entre ficar à sombra ou ao sol. A questão é que para os nossos olhos, esse era o único benefício do terreno. E as crianças, o que faziam enquanto estranhávamos o local? Elas pesquisavam, equilibravam, contavam folhas, escalam, exercitavam corpo e pensamento em um espaço denominado pelo professor de Educação Física como Quintal vivo.

\section{Foto 3. Escalando uma teia e Foto 4: Composição com carrinho de mão.}

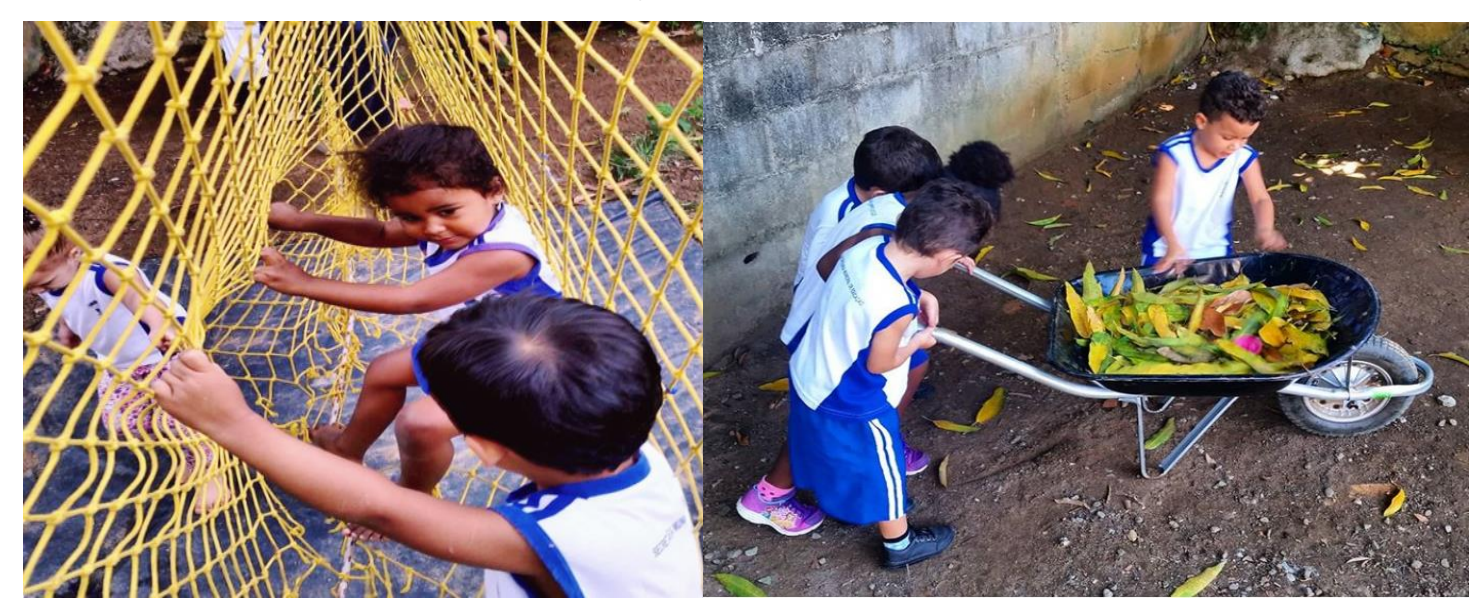

Fonte: Aula de educação física no centro de educação infantil. 
Cada criança lançou mão de um pneu ou até mesmo da metade de um pneu, já estavam brincando com caixas; das garrafas vazias faziam chocalhos colocando as britas que compunham o terreno. Em um carrinho de mão se equilibravam na tentativa de não derrubarem o que haviam colhido. Em um pequeno muro de pedras, fizeram um caminho equilibrando - se, e, de alguma maneira, sabiam que para se equilibrar em um local suspenso, devemos abrir os braços para termos mais equilíbrio.

\section{Foto 5. Equilibristas.}



Fonte: aula de educação física no centro de educação infantil.

No local havia também lupas disputadíssimas. Talvez, o único objeto que possibilitasse uma troca pelo carrinho de mão. Através delas, visualizavam as colmeias de abelhas sem ferrão, trazidas pelo professor e inseridas no muro da escola, em pequena quantidade há algum tempo e que hoje possui três colmeias.

\section{Foto 6. Encontro com abelhas.}

Fonte: Aula de educação física no centro de educação infantil.

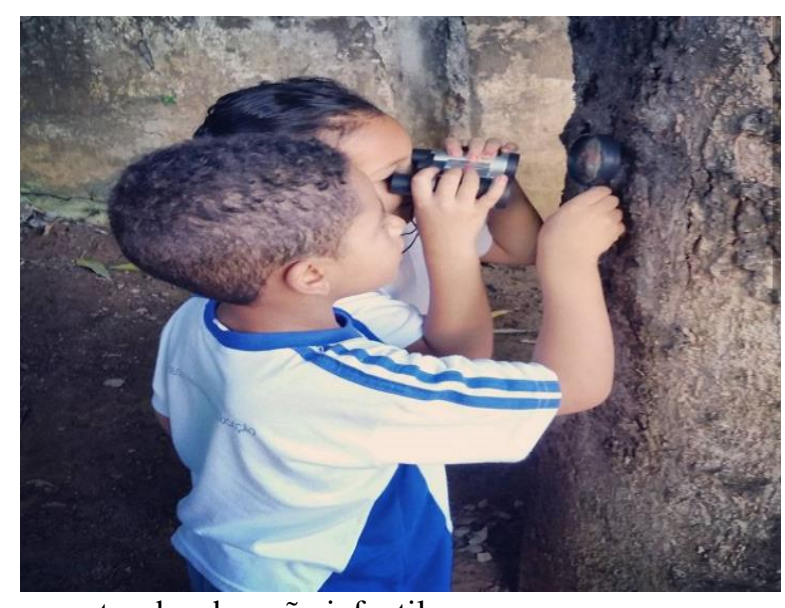


As abelhas "sem ferrão" são as abelhas Jataí, também denominadas abelhas sociais. Recebem esse nome por serem animais que não oferecem riscos, podendo ser cultivadas até mesmo em apartamentos como animais domésticos. São polinizadoras, portanto, sua presença no espaço "Quintal Vivo" proporciona ao professor um trabalho de consciência ecológica com as crianças, falando sobre a importância das mesmas, especialmente no que diz respeito à produção de frutas como o maracujá, tomate e a laranja, que não reproduziriam caso as abelhas não fizessem esse trabalho.

Ao se aproximarem das abelhas pela primeira vez, as crianças apresentam muita insegurança por conhecerem as abelhas como um animal que pode proporcionar uma dolorosa picada, mas ao ouvir as explicações do professor, sentem-se mais seguras e ao final da aula, já conseguem chegar perto das abelhas de forma carinhosa, conta o professor.

Ainda dentro desse espaço, que agora podemos adjetivá-lo como um lugar agradável, algumas crianças que ficavam muito quietas em um canto, faziam em suas imaginações "tortas de abacate com chocolate e recheio de uva".

\section{Foto 7. Torta de abacate.}



Fonte: Aula de educação física no CMEI.

Labirintos com os pneus era o que não faltava. Algumas crianças colhiam goiabas com um cano, de maneira que ao utilizar o cano, treinavam o equilíbrio de mantê-lo erguido.

Henrique, por estar com as pernas engessadas, se ajeitava sempre em algum brinquedo, sem que ninguém dissesse: esse pode, esse não pode. Dentro de seus limites, Henrique cria brinquedos como amarelinha que, ao invés de quadrados, como conhecemos, são feitas com as partes de pneus. Devido ao uso do gesso, não pula com um pé só, como costumamos presenciar em brincadeiras de amarelinha, pula sempre com os dois pés. Ele sempre se ajeita e se diverte. 
Sandro brincava com as panelinhas criando comidinhas com folhas e nos oferecendo para degustação. É uma criança que costuma ficar em silêncio brincando de maneira bastante concentrada e às vezes acompanha os adultos com um olhar de quem simula um riso. A Iara adora subir em árvores e também dançar, especialmente o samba.

Assim, fomos modificando nosso olhar em relação àquele espaço e percebendo que ali era um local que cabiam todos, pois, em uma aula de Educação Física com atividades programadas/ prontas, talvez não houvesse lugar para uma criança em condição especial como Henrique. Isso só era possível porque ali encontrava não somente "um" professor que cria, mas que também permite essa criação a partir dos pequenos.

Aquele que cria é aquele que adota um ponto de vista criador. Aquele que raspa, escova, faxina os clichês do senso comum e das formas legitimadas. Aquele que enfrenta o desafio de explicar suas criações, sem apelar para uma infância criadora, superior e extrínseca a ele e a seu fazer. Aquele que distingue criação de criatividade; considerando a criatividade, apenas como uma parte da criação; o qual é mais amplo e envolve invenção dos próprios problemas. Aquele educador que sabe que a criação é sempre um processo de autocriação, de criação de si; ou seja, um diferenciar, diferenciando-se (CORAZZA, 2013. p. 97- 98).

Fomos viajando pelo espaço escola e nosso estranhamento foi dando lugar a descobertas. Assim, passamos a nos permitir ver de outro modo, sabendo que as características do local podem ser modificadas, pela relação que temos com ele. Ali, presenciávamos afirmações curriculares e de aprendizagens como possibilidade de invenção de outros modos de relação e vida em um devir alegre de um corpo escola.

Corpo capaz de afetar-se também pelas forças da sua época e do momento preciso em que atua. [...] torna-se uma experiência de deviroutro, aprendendo a afetar e ser afetado, envolvendo uma atitude de escuta do mundo com o corpo todo, um estado de alerta e ao mesmo tempo de grande entrega e disponibilidade (KASPER, 2009, p. 206).

Um deviroutro é convocado quando o choro que ocorre entre as crianças nas aulas, na maioria das vezes pela disputa para brincar com o carrinho de mão ou as lupas, é transformado em risos quando o professor começa a cantar: "chora, não vou ligar, não vou ligar, chegou a hora, vai me pagar, pode chorar, pode chorar...", música da Beth Carvalho, e automaticamente esse choro se transforma em riso. 
Indagamos, assim, o que pode um professor? O que pode uma relação de invenção do espaço escolar? Passamos a nos questionar ainda sobre as diferentes docências produzidas no mesmo espaço e do desconhecimento da própria escola da potência do seu trabalho.

Em uma segunda feira, em que ao ver uma coleguinha chegar aos prantos, por ter sido levada para a escola pelo pai, enquanto gostaria que a mãe a levasse, Henrique diz: "todo mundo me traz e eu não choro"! O menino deixou claro que várias pessoas do abrigo transitam com ele. Pessoas também são nômades em sua vida.

Ao iniciar outro dia de aula, a professora sempre escolhe algumas crianças para fazer a contagem da turma. Uma criança nesse dia se recusou a contar. Disse que tinha medo de errar. Explicamos que também estudamos e também erramos. Mas outra criança diz:

— Todo mundo erra não é tia?

Henrique diz: - Sua mãe não briga quando você erra? Você briga com a sua filha quando ela erra?

Essa pergunta nos provocou a pensar qual o entendimento de mãe essa criança tem? Será que mãe é visto como algo nocivo em sua vida? Afinal, ele tem mais dois irmãos que vivem em situação parecida com a sua.

O interessante é que no horário das refeições, Henrique e Luan se veem. Quando se avistam, muito embora um ou outro esteja sentado fazendo as refeições, levantam, se abraçam e voltam para o seu lugar, já que pertencem a turmas diferentes, sem que alguém fale qualquer coisa. Henrique apenas diz: é meu irmão, tia.

Sandro quase não fala dentro da sala de aula. Ao levá-lo ao banheiro, pudemos perceber que suas idas constantes são para reencontrar seu irmão Antônio, que tem cinco anos e se encontra em uma sala que dá acesso ao corredor da qual ele tem que passar para ir ao banheiro. Quando encontra o irmão no corredor, dá um forte abraço, mas quando não o encontra, passa direto para o banheiro, mas na volta, não dá outra, escala a "meia porta" e dá uma olhadinha no irmão, que na grande maioria das vezes não o percebe. Ele diz: meu irmão, tia e volta para a sala. É uma das poucas vezes que ouvimos sua voz.

O esquizo está presente e ausente [...], ocupa um território, mas ao mesmo tempo o desmancha, dificilmente entra em confronto direto com aquilo que recusa, não aceita a dialética da oposição, que sabe submetida de antemão ao campo do adversário, por isso ele desliza, escorrega, recusa o jogo ou subverte - lhe o sentido, corrói o próprio campo e assim resiste às injunções dominantes. O nômade a exemplo do esquizo é o 
desterritorializado por excelência, aquele que foge e faz tudo fugir. Ele faz da própria desterritorialização um território subjetivo (PELBART, 2011, p. 20).

Ao perguntar Sandro sobre a Casa Rosa, responde:

- Eu moro na casa rosa. Eu não gosto de morar lá. A tia não gosta de mim. Eu faço muita bagunça.

—E qual a bagunça você faz? - Perguntamos e ele respondeu:

- Capoeira, mas é só abrir as pernas, tia.

\section{Foto 8. Apresentando a capoeira.}



Fonte: Acervo do professor de educação física.

- Porque você não gosta da Casa Rosa?

- Porque eu tenho mãe. A tia não dá o telefone da minha mãe.

Ao interrogá-lo sobre o que tem de legal na Casa Rosa, diz: "borboleta, carrinho novo, Superman, Max Still”.

Sandro nos provoca a pensar que mesmo entre um desjejum, uma atividade, uma ida ao banheiro, uma brincadeira; existem maneiras de modificar os espaços predeterminados e que talvez, a escola ainda seja um dos poucos espaços que lhes restam para expressar seus desejos.

\section{DOCÊNCIAS E RELAÇÕES NÔMADES}

Buscamos uma conversa sobre nossas observações com os professores, que ora se davam pelo espaço de educação física, corredor, sala de aula ou refeitório, estando atentas às oportunidades 
dos diferentes espaços, tempos e relações. Um dia, após o desjejum na turma dos bebês com os ânimos menos exaltados, a professora da turma argumentou:

No ano passado, eu fiquei com uma turma de quatro anos e foi interessante perceber que quando as crianças do abrigo chegam aqui, elas elegem uma professora e todas as ações, só conseguem fazer de mãos dadas a essa pessoa. Na hora de irem embora, os maiores carregam a mochila dos menores e dão as mãos. Eu não vejo isso acontecer com outras crianças. Teve até o caso de um menino que foi adotado, mas continuou a estudar aqui. Na hora de ir embora, se mostrava confuso e falava: eu não sei se eu vou para minha fazenda ou vou ficar com os meus amigos. A família adotiva o tirou dessa escola (Professora do Grupo I).

Ao conversarmos com a diretora da escola sobre a história de vida das crianças, ela diz que o que sabe se dá por meio do relato de psicólogas, assistentes sociais que vem à escola para conversar. Ela faz as seguintes colocações:

Na semana passada, a psicóloga veio aqui para conversar um pouquinho sobre a vida de cada um e as histórias são as mais variadas. Tem criança que vivencia situação de violência, e é retirada da família, pais que fazem o uso de drogas, então, são $\mathrm{N}$ situações e a maioria delas é situação de violência em casa e sempre há a tentativa de que essa família se reestruture para que a criança retorne à sua família ou alguém da família. Quando isso não é possível, aí sim, a criança vai para uma adoção, mas quando isso é possível, é feito todo um trabalho tanto com a criança, quanto com a família para que ela retorne aos seus familiares.

Continuando nossa conversa, agora com a diretora e a pedagoga juntas, perguntamos sobre quando as crianças chegam ao CMEI, como a escola percebe e trabalha com suas diferenças?

Não percebo, inclusive falei com a psicóloga; olha, eu consigo visualizar cada criança que você está me falando, mas nós temos dificuldades de associar, exceto o Henrique porque tem o gesso e esse acompanhamento que a gente faz, não é, é uma criança que está sempre em evidência, agora, os outros, não é porque, há, é porque é do abrigo. Porque assim, não fica com esse estigma, não é, há, esse é da instituição, esse não é, a gente tem dificuldade de associar quem é do abrigo, está todo mundo incluído, graças a Deus (Diretora).

Quanto ao acolhimento, o mesmo é feito para todos. A mesma proposta que é pensada em termos de acolhimento para todas as crianças é igual. E.... não sei onde está, mas a gente tem aqui criança soropositivo. É tão normal para a gente que não sei nem onde está. Nós estamos tão acostumadas a agir sem preconceito que agora que eu me dei conta de uma criança do grupo 3. Mas a questão é que a criança não fica o tempo todo 
com a gente. Algumas retornam para a família, outras são adotadas, então, muitas vezes a gente inicia o ano, depois, não vê mais a criança (Diretora).

Acontece aqui também com o Luan e Henrique, ficaram nessa expectativa de adoção e depois não foram adotados. Isso acabou mexendo com as crianças. No ano passado o Henrique e Luan estavam muito agitados e ninguém passou isso para nós. No final do ano é que eu fui ver uma pessoa que veio buscá-los aqui na escola com autorização do abrigo e aí é que eu soube que essa pessoa estava sondando a possibilidade de adoção e a gente parou para pensar, será que ele vê como uma boa? É bom a gente saber o que ele pensa (Pedagoga).

O dia das mães a gente não comemora dia de mãe e dia de pai. Mas não tem como fugir disso porque a mídia traz, tá na propaganda na televisão. O que nós colocamos aqui é que se faça um cartãozinho para quem a criança deseja homenagear, que seja a mãe, ou um cuidador do abrigo, que seja até mesmo uma pessoa mais próxima como a professora, alguém que ela goste e que queira homenagear, da sua família ou de quem cuida dela (Pedagoga).

E nossa conversa continua pela escola, com professores das diferentes salas de aulas e grupos etários sobre a relação com as crianças, com os currículos, com os fazeres de cada dia e sobre como as crianças expressam seus desejos e aprendizagens.

Quanto às crianças do abrigo quando chegam aqui, não tem diferença. Adulto é que tem resistência a mudanças. Criança se adapta em qualquer escola, em qualquer ambiente, não é, elas podem até dar sinais de coisas que estão vivenciando, mas isso requer de nós um olhar mais cuidadoso, o ouvir, ou... parar para ouvir, perguntar se está gostando. Não é se expor, mas perguntar se tem algo angustiando aquela criança. Não é exatamente uma comparação, mas é uma oportunidade para que a criança se exponha porque tanto na criança quanto no adulto, parece que soluciona melhor (Professora).

O que a gente percebe muito, é a saudade. Eles falam da mãe, falam do pai, do irmão.

Quando eu cheguei aqui com outros três colegas na Educação infantil, foi meio estranho porque era uma matéria entrando de forma específica, então foi muito estranho, ou seja, por sermos homens, fomos recebidos com uma certa estranheza por parte de um grupo em um trabalho executado por mulheres, e aí, quando a gente se deparou com a educação física na educação infantil, víamos que muito do que tinha na faculdade estava muito longe do tinha na realidade da escola, lá, não ensinaram a gente a trabalhar com educação infantil. Ensinavam conceitos esportivos de faixa etárias maiores e a educação infantil ficava muito longe do ideal, até mesmo as 
literaturas, nós tínhamos pouco acesso. Então, quando nós chegamos aqui, nos deparamos com esse gargalo. O que fazer? Aí, o tempo foi de tentar descobrir, conversar e foi quando nós conhecemos uma excelente Pedagoga chamada Janete que hoje está na SEME. Mesmo não tendo ideia do que fazer, começamos a dialogar com a Pedagoga sobre tudo isso, por exemplo, o que se faz de educação física com essas crianças? Então, mesmo sem ter uma noção exata do que trabalhar, começamos a chegar ao seguinte debate: o que é que cada criança, cada faixa etária precisa? (Professor de Educação Física).

Até mesmo para uma questão, um desenvolvimento motor ou cognitivo, qual é a necessidade de cada um? Assim, começamos a perceber que não dava para trabalhar de maneira igual com todo mundo, percebemos que não dava para proporcionar um quintal e esperar uma resposta igual de todos porque a faixa etária é diferente, também a perspectiva de altura e forma de ver o mundo, cada um tem a sua. Isso se deu para nós numa forma de descoberta mesmo.

A cada momento em que eu colocava uma experiência, a criança me dava uma resposta, então, eu fotografava, filmava e aí, muito do que eu oferecia, eu guardava as respostas; mais à frente, eu usava aquela resposta com a criança, assim fomos percebendo que elas criavam em cima do que nós propúnhamos, mas também criavam por elas próprias, independente de nossas propostas (Professor de Educação Física).

É claro que alguns professores têm uma linha mais diretiva, mas eu sou mais de propor e não de dirigir atividade. Gosto de disponibilizar o espaço e deixar que a criança crie a partir daquele espaço. Há necessidade de intervenção, oferecer algo. $\mathrm{O}$ quintal é livre, mas se eu coloco um pneu, já crio uma outra possibilidade de brinquedo. Aí, tem dias que eu tiro, coloco outra coisa, e a gente vai dando outras possibilidades de brincar. São elementos que ajudam as crianças a criar. Quando nós fazemos uma atividade dirigida como a tirolesa, enquanto um está nessa atividade, o outro está em outra coisa, como, por exemplo, brincando de comidinha, casinha, panelinha; e quando ele quiser brincar com a atividade proposta ele volta porque eu não obrigo a criança a ficar naquele lance do tipo tem que fazer isso, tem que fazer aquilo, tem que andar em fila. Você já andou em fila com a mão no ombro de outra pessoa? É horrível!

Aqui, vem quem quer e quando eu menos espero, todo mundo está participando e se sentindo à vontade, sem aquela disputa e eu acabo não fazendo nada excessivamente dirigido para as crianças. Essa é a lógica do meu trabalho (Professor de Educação Física). 
Nós chamamos esse projeto aqui de quintal vivo. Ele é bem antigo, nós já usávamos esse espaço em 2006 porque as crianças curtem muito isso. Quando nós vemos as crianças brincando em grupinho, cada grupo de três, quatro é um universo de invenção que nós não fazemos a mínima ideia do que seja. Eles criam ali dentro daquele espaço e juntos manuseiam a terra, trabalham o imaginário e tem toda uma ligação com a realidade deles. Eu acho legal isso porque vejo o que é que posso tirar de feedback. O que é que eu posso trazer para a criança fazer além daquilo? Então, eu tenho essa prática.

Aqui, estamos o tempo todo em contato com a natureza. Aqui, nós apresentamos as abelhas. Tem hora que eles esquecem, aí, um do grupo lembra que elas estão aqui junto com eles. Aqui aparecem também borboleta, minhoca, joaninha, centopeia e sempre rola uma grande discussão do tipo, se pica ou não. O interessante é que o grupo inteiro se debruça sobre o bicho, até parece que são conhecedores daquele bicho. Risos. Raramente trazemos brinquedos prontos. Aqui, trabalhamos com os descartáveis, ou as vezes, com o próprio corpo, porque uma coisa é eu entregar o brinquedo pronto, outra coisa é a possibilidade de criar, além de tudo, o brinquedo pronto dá muito conflito porque esteticamente ele é bonito, então a criança cria um sentimento de posse, também começa a pensar que o brinquedo pronto só serve para trabalhar de uma única maneira. Já a vasilha de plástico é tudo. É panela, é prato, é celular... (Professor de Educação Física).

$\mathrm{O}$ brinquedo pronto não me deixa à vontade para trabalhar, eu ainda tenho muita resistência com isso, acho que aqui não é o local. Eu ainda prefiro a criação das crianças com os galhos, que às vezes viram um lápis, pazinha, as pedras viram docinhos e aí, quando chega um adulto que não conhece a lógica, diz: há, mas não tem brinquedo aqui. Ela não percebe que o brinquedo está aqui, porque o outro está aqui; o corpo da criança está aqui; então, não necessariamente precisa de objeto pronto. A criança precisa vivenciar também as coisas da natureza e os objetos comuns. Por isso, a grande maioria das nossas ações aqui são propositivas e não, prontas. Nós usamos pneus, cordas e tantas outras coisas e sempre tivemos resultado vantajoso (Professor de Educação Física).

Foram muitas interseções nas colocações do corpo docente, do corpo administrativopedagógico e das crianças, especialmente das crianças nômades. Compreender o sentido dessas falas dos sujeitos que vivem esse cotidiano é trilhar por um "caminho por meio do qual buscamos novas possibilidades de compreensão da realidade social” (CARVALHO, 2009, p. 18). 
As situações de produção de infâncias e currículos nômades surgem a todo tempo nas falas dos sujeitos imbricados no fazer cotidiano da educação infantil, desde o argumento sobre o pouco conhecimento da história de vida das crianças, aos enredamentos das histórias contadas pelas crianças em invenções de descobertas das suas necessidades por docências sensíveis que querem escutar o que cada criança precisa e consegue experimentar corporalmente e cognitivamente por uma vida mais bonita na escola.

O que se percebe nesse espaço nômade chamado escola são composições curriculares estrangeiras, que podem apontar movimentos sensíveis aos fazeres escolares que buscam sentidos intensivos que, somente podem ser experimentados a partir da relação com as crianças e suas movimentações diferenciais por entre casas lares, ensaios de adoções e atitudes de acolhimento na escola por entre crianças que levam os menores pelas mãos e docências que, partem do que as crianças precisam, oportunizando fazeres alegres e inventivos.

A pedagoga comenta que em um caso de ensaio de uma adoção de dois irmãos, através de passeios com os pretensos futuros pais; em locais turísticos do estado, como shoppings, praças, etc.; acompanhados de algum funcionário do abrigo; aconteceu de um casal não passar no teste de adoção, por algum motivo, do qual não tivemos conhecimento. O casal deu a notícia de que não os adotaria:

Nós não vamos poder levar vocês para morar com a gente porque antes disso, tinha que fazer uma prova e nós não passamos nessa prova. Ouvindo isso, o irmão mais velho disse: eu te ensino a fazer a prova tia!

São muitas histórias que refletem claramente os sentimentos, emoções e/ ou expectativas das crianças e um querer fazer parte de uma nova família. A escola se apresenta como um espaço onde isso aparece nas conversas. São sentimentos que podem vir à tona em uma conversa ou até mesmo passar como imperceptíveis.

As crianças sentem saudade das pessoas que passam por suas vidas. São idas e vindas de professores, a saudade dos pais biológicos, dos amigos que já foram adotados, de funcionários do abrigo que se colocam para as crianças como sendo da família, mas em algum momento deixam de trabalhar ali e também a saudade dos pretensos pais; aqueles que "não passam nas provas", mas que em seus ensaios de adoção, realizam passeios, momentos divertidos, podendo durar dias ou meses, proporcionado também um vínculo.

Com o discurso de que "estão todos incluídos", encontramos também na escola, como aponta Candau e Moreira (2013), a forma assimilacionista de educação, favorecendo com que todos estejam na escola, sem que a matriz da mesma seja modificada. Mas a escola também é feita de 
pessoas que se deixam levar por desejos contagiantes como práticas de liberdade e afirmação do possível.

Destacamos a importância da articulação da Pedagoga, em que ao disponibilizar suas aprendizagens e compor com os professores da Educação Física, promove vivências no espaço escolar, permitindo que todas as crianças participem das aulas de maneira singular. Aliado à articulação professor-pedagogo, soma-se a potência dos registros docentes que potencializam aulas que podem ser revisadas, modificadas e reinventadas.

Os registros de produção das crianças modificaram os conhecimentos docentes, possibilitando novos modos na elaboração de atividades a serem desenvolvidas a partir do que as crianças produziam, permitindo a continuidade ou modificação dos trabalhos; enquanto currículo itinerante, como apontado por Corazza (2013), que engendra, percorre, e que faz fugir a tudo que configure algo fixo, se fazendo por interações, ou como aqui denominamos currículos nômades.

Os nomadismos curriculares experimentados nesse cotidiano escolar ajudam a "pensar educação a partir do par experiência-sentido" (LARROSA, 2002, p.20), como abertura de aprendizagens com as crianças, não se eximindo em tamborilar, estimular, construir, transformar, criar...com as infâncias nômades como potências que entrecruzam o sedentarismo e transformam escolas e docências. A questão que permanece é como produzir docências nômades, para que as infâncias se proliferem como potências e as diferenças nos permitam crescer e sermos outros? 


\section{REFERÊNCIAS}

AMORIM, Antônio Carlos Rodrigues de; ROMAGUERA, Alda Regina Tognini. Currículo, linhas de suspensão. In: FERRAÇO, Carlos Eduardo; RANGEL, Iguatemi; CARVALHO, Janete Magalhães; NUNES, Kezia Rodrigues. Diferentes perspectivas de currículo na atualidade. Petrópolis, RJ: De Petrus: NUPEC/UFES, 2015.

BRASIL. Lei 8.069 de 13 de julho de 1990. Estatuto da Criança e Adolescente - ECA. Diário Oficial da União. Poder Legislativo, Brasília, 16 jul. 1990, Seção I, p. 13.563. Disponível em: <www.tjdft.jus.br/cidadaos/infancia-e-juventude/ informacoes/situacao-de-risco-1>. Acesso em: 01 maio 2018.

Ministério da Educação e Cultura. Secretaria de Educação Básica. Diretrizes curriculares nacionais para a Educação Infantil; Secretaria de Educação Básica. - Brasília : MEC, SEB, 2010.

CANDAU, Vera Maria, MOREIRA, Antônio Flávio. Multiculturalismo: diferenças culturais e práticas pedagógicas. Petrópolis, RJ: Vozes, 2013. p. 20 - 21.

CARVAlHO, Janete Magalhães. O Cotidiano Escolar como comunidade de afetos. Petrópolis, RJ: DP et Alii; Brasília, DF: CNPq, 2009.

CORAZZA, Sandra Mara. O que se transcria em educação? Porto Alegre: UFRGS. Doisa, 2013.

CRUZ, Lílian Rodrigues, HILLESHEIM, Betina, "Não sei estudar parada": inclusão e nomadismo. Universidade de Santa Cruz do Sul, Santa Cruz do Sul, RS, Brasil, 2011. vol. 1, n. 1.

KASPER, Katia Maria. Experimentar, devir, contagiar: o que pode um corpo? Campinas, v. 20 , n. 3 (60), p. 199213, set./dez. 2009. Disponível em: <http://www.scielo.br/pdf/pp/v20n3/v20n3a13>. Acesso em: 30 abr. 18.

KOHAN, Walter Omar. Visões Filosofia: infância. Alea. Rio de Janeiro, vol. 17/02. p. 216-226, jul./dez. 2015.

LARROSA, Jorge. Notas sobre a experiência e o saber de experiência. In: Revista Brasileira da Educação, n. 19, p. 20-28, jan./abr. 2002.

LINS, Daniel. Mangue's school ou por uma pedagogia rizomática. Educ. Soc. Campinas, vol. 26, n. 93, p. 1229-1256, set. /dez. 2005. Disponível em: <http://www.scielo.br/pdf/es/v26n93/27277.pdf>. Visitado em: 05/11/2017.

PELBART, Peter Pál. Vida Capital: ensaios de biopolítica. São Paulo: Iluminuras, 2011.

PEREZ, Carmem Lúcia Vidal; SAMPAIO, Carmen Sanches. Conversas sobre aprenderensinar a ler e a escrever.. São Paulo: Cortez, 2012. p. 394-427.

PRATES, Maria Riziane C.; RODRIGUES, Larissa Ferreira. Colorindo o currículo: outros possíveis pela experiência na infância. Petrópolis, RJ: DP et Alii; 2012.

PUCHEU, Alberto. A fronteira desguarnecida. Revista Digital do LAV. Santa Maria, vol. 7, n. 2, p. 66-77 - mai. /ago. 2014. Disponível em: <https://www.dicio.com.br/nomade-2/>. Acesso em: 23 out. 17.

ROLNIK, Suely. Cartografia Sentimental: transformações contemporâneas do desejo. Porto Alegre: sulina, 2006. 


\section{RESUMO}

Trata de inquietações sobre currículos e infâncias, objetivando compreender a relação produzida entre professores e crianças e a condição de nomadismo nos contextos de aprendizagens de um Centro de Educação Infantil no município de Vitória - ES. As contribuições teórico-metodológicas são de Rolnik, Pelbart, Larrosa, Carvalho, dentre outros, pela cartografia das paisagens escolares e as redes de conversações que podem desterritorializar modos de tecer conhecimentos na escola. Conclui que os nomadismos curriculares inventados por crianças e professores ajudam a pensar a educação como experiência-sentido, pela diferença como força que entrecruza o sedentarismo e transforma aprendizagens, infâncias e docências.

Palavras-chave: Currículos. Infâncias. Nomadismo.

\section{RESUMES AND CHILDHOOD NOMADES}

\section{ABSTRACT}

Dealing with concerns about resumes and childhood, in order to understand the relation between teachers and children and produced the condition of nomadism in learning contexts of an early childhood Center in the municipality of Vitória-ES. The theoretical-methodological contributions are Rolnik, Pelbart, Larrosa, oak, among others, by the cartography of landscapes and conversations that networks can desterritorializar ways to make knowledge in school. Concludes that the curricular nomadismos invented by kids and teachers help thinking education as experience-sense, the difference as a force that intersects the sedentary lifestyle and transforms learning, childhood and docências.

Keywords: Resumes. Childhood. Nomadism.

\section{HOJAS DE VIDA Y NIÑEZ NOMADES}

\section{RESUMEN}

Abordar preocupaciones sobre hojas de vida y la niñez, para entender la relación entre maestros y niños y produce la condición de nomadismo en el aprendizaje de los contextos de una infancia centro en el municipio de Vitória-ES. Las aportaciones teórico metodológicas son Rolnik, Pelbart, Larrosa, roble, entre otros, por la cartografía de paisajes y conversaciones que redes pueden desterritorializar las maneras para hacer conocimiento en la escuela. Concluye que los nomadismos curricular inventado por los niños y maestros ayudan a la educación del pensamiento como experiencia de sentido, la diferencia como una fuerza que se cruza con el estilo de vida sedentario y transforma el aprendizaje, infancia y docências.

Palabras-clave: Hojas de vida. Niñez. Nomadismo. 